\title{
OS LIMITES JURÍDICOS PARA A PROTEÇÃO AMBIENTAL: OS DIREITOS DOS HUMANOS EM FACE DOS SERES NÃO HUMANOS
}

\author{
LEGAL LIMITS FOR ENVIRONMENTAL PROTECTION: HUMAN \\ RIGHTS IN THE FACE OF NON-HUMAN BEINGS
}

\section{Luciano Costa Miguel ${ }^{1}$}

1 Doutorando e Mestre em Direito Ambiental pela Escola Superior Dom Helder Câmara. Professor da Dom Helder Câmara. Procurador da Fazenda Nacional. E-mail: lucianocmiguel@hotmail.com

RESUMO: Ante o advento dos ambientalistas, que atualmente apresentam demandas para expansão da proteção jurídica para todos os seres vivos, é necessário verificar se a legislação brasileira está apta para reconhecer e salvaguardar os direitos dos não humanos e quais limites jurídicos existem para esses direitos. Assim, será analisada a compatibilidade do paradigma ecocêntrico junto à centralidade do homem como sujeito de todos os direitos. Prática de rodeios, sacrifícios de animais e relação direitos econômicos e ecológicos serão analisados objetivando solucionar concorrências entre esses direitos. Pretende-se esclarecer os limites impostos pela legislação para proteção do bem-estar e da vida dos animais.

Palavras-chave: Direito ao desenvolvimento. Direitos culturais. Direitos dos animais. Diretos dos humanos. Liberdade religiosa.

\begin{abstract}
In view of the advent of environmentalists, who currently have demands to expand legal protection for all living beings, it is necessary to verify whether Brazilian legislation is able to recognize and safeguard the rights of non-humans and what legal limits exist for these rights. Thus, the compatibility of the ecocentric paradigm with the centrality of man as the subject of all rights will be analyzed. Rodeo practices, animal sacrifices and the relationship between economic and ecological rights will be analyzed in order to resolve competition between these rights. It is intended to clarify the limits imposed by legislation to protect the welfare and life of animals.

Keywords: Animal rights. Cultural rights. Human rights. Right to development. Religious freedom.

Sumário: Introdução - 1 O Paradigma Antropocêntrico da atual Ordem Jurídica Nacional - 2 A Natureza Jurídica dos Animais - 3 Os Limites dos Direitos Culturais e Religiosos dos Humanos em face dos Não Humanos - 4 Os Limites Impostos pelos Direitos Econômicos dos Humanos em face dos Não Humanos Considerações Finais - Referências
\end{abstract}

\section{INTRODUÇÃO}

Como resposta ao perigoso estágio de deterioração do meio ambiente levado à cabo pela humanidade nas últimas décadas, o movimento ambientalista exsurgiu em âmbito nacional e mundial, fortalecendo as demandas sociais e propostas jurídicas que, até então, eram pouco tratadas e refletidas pelas teorias jurídicas mais tradicional, como o reconhecimento dos direitos dos animais.

Afora os evidentes excessos praticados pelas correntes ambientalistas mais radicais, como o ecoterrorismo, a maioria das atuações, pautas e proposições teóricas apresentadas pelos defensores da causa ambiental merecem um exame de juridicidade mais acurado diante do ordenamento jurídico. Temas como o sacrifício de animais em cultos religiosos e a utilização de animais em manifestações culturais colocam em choque as correntes ambientalistas ecocêntrica e antropocêntrica, demonstrando a real necessidade de se investigar os limites da proteção ambiental ante a necessidade de se atender aos outros direitos fundamentais do homem, como a liberdade de culto e de crença e o respeito à diversidade cultural. 
O presente trabalho não pretende limitar o debate na categorização dos animais como objetos ou sujeitos de direitos, com ou sem personalidade, mas tratar de forma ampla acerca da existência de limites à finalidade da preservação do meio ambiente como um todo e em suas diversas dimensões (natural, urbano e cultural) ante a inequívoca centralidade do homem e dos seus direitos no direito positivado.

Após a exposição de algumas conclusões jurídicas, será verificado se, de fato, há na atual crise civilizacional uma relação dicotômica entre economia e ecologia ou entre os homens e os demais animais. Para isso, será demonstrado que a atual crise ambiental e a crise do capitalismo possuem pontos de conexão que devem ser mais bem averiguados para responder a essa questão.

Com esse intuito, será adotado o método dedutivo e bibliográfico, procedendo-se à análise da compatibilidade jurídica dessas propostas ambientalistas ante o ordenamento jurídico positivado, ou seja, reconhecendo o atual estágio do direito positivo como limite ou ao menos um filtro para algumas dessas atuais demandas socioambientais.

\section{O PARADIGMA ANTROPOCÊNTRICO DA ATUAL ORDEM JURÍDICA NA- CIONAL}

Não se coloca em dúvidas que a maior parte das propostas e demandas apresentadas pelos diversos movimentos ambientalistas ao redor do mundo, nessas últimas décadas, são legítimas e merecedoras de ponderadas considerações por parte das mais altas autoridades, inclusive com a necessidade de urgente concretização nos mais diversos setores da sociedade (público, privado e terceiro setor).

A própria concepção de democracia deliberativa proposta por Habermas 1997) caminha nesse sentido de que a democracia não pode ser compreendida como um mero discurso da maioria, devendo ser aberta a possibilidade de Organizações Não Governamentais (ONG), intelectuais ativistas, organizações religiosas, ou mesmo um único indivíduo (cidadão ou não), de se colocarem no debate público e exporem as suas pautas sociais.

Contudo, quando se faz uma análise jurídica mais acurada, percebe-se algum excesso nas pautas ambientais que, simplesmente, não podem ser atendidas, sob pena de violação a outros direitos fundamentais individuais e coletivos previstos no texto da Constituição da República Federativa do Brasil (CRFB). Em que pese se admita a necessidade de uma leitura mais moderada, pode-se afirmar que a ordem jurídica nacional é toda fundada no paradigma antropocêntrico, porquanto coloca o homem de forma clara como referência e medida de todas as coisas (FIUZA e GONTIJO, 2015), para se utilizar a expressão de Protágoras.

O Brasil tem como fundamento a dignidade da pessoa humana, pela previsão na CRFB/1988, quando determina que "Art. $1^{\circ}$ - A República Federativa do Brasil, formada pela união indissolúvel dos Estados e Municípios e do Distrito Federal, constitui-se em Estado Democrático de Direito e tem como fundamentos: [...] III - a dignidade da pessoa humanada". Além disso, todos os direitos e garantias fundamentais, sejam individuais, coletivos (Art. $5^{\circ}$ ), sociais (Art. $6^{\circ}$ ) ou ambientais (Art. 225) têm como única destinatária a vida humana em condições dignas e sadias. Mesmo o direito ao meio ambiente equilibrado, que, segundo o caput do art. 225, é direito de todos, tem como destinatário todos os seres humanos (BRASIL,

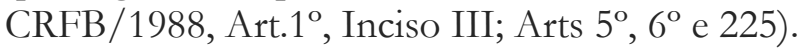

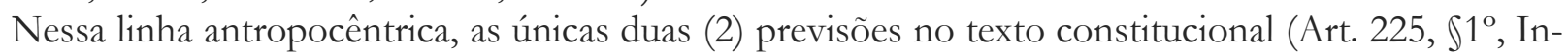
ciso VII, $\left(7^{\circ}\right.$ ) que usam de forma expressa a expressão animais, vinculam a sua proteção para assegurar a efetividade do direito de todos (os seres humanos) ao meio ambiente ecologicamente equilibrado, em vista do seu caráter essencial à sadia qualidade de vida das pessoas humanas:

Art. 225. Todos têm direito ao meio ambiente ecologicamente equilibrado, bem de uso comum do povo e essencial à sadia qualidade de vida, impondo-se ao Poder Público e à coletividade o dever de defendêlo e preservá-lo para as presentes e futuras gerações.

$\int 1^{\circ}$ Para assegurar a efetividade desse direito, incumbe ao Poder Público:

$[\ldots]$ 
VII - proteger a fauna e a flora, vedadas, na forma da lei, as práticas que coloquem em risco sua função ecológica, provoquem a extinção de espécies ou submetam os animais a crueldade.

$[\ldots]$

$\int 7^{\circ}$ Para fins do disposto na parte final do inciso VII do $\mathbb{S} 1^{\circ}$ deste artigo, não se consideram cruéis as práticas desportivas que utilizem animais, desde que sejam manifestações culturais, conforme $o \$ 1^{\circ}$ do art. 215 desta Constituição Federal, registradas como bem de natureza imaterial integrante do patrimônio cultural brasileiro, devendo ser regulamentadas por lei específica que assegure o bem-estar dos animais envolvidos - Incluído pela Emenda Constitucional $\mathrm{n}^{\circ} 96$, de

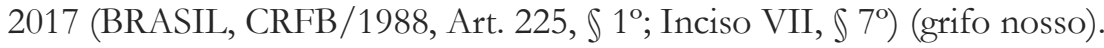

Em outras palavras, percebe-se que o legislador constituinte deixou claro que a preservação dos demais animais se dá na medida em que se torna necessário assegurar a efetividade do direito de todos (os seres humanos) ao meio ambiente equilibrado. Ou seja, a proteção dos animais e de todos os outros elementos que compõem o meio ambiente é simplesmente um meio para se chegar ao fỉm, que é a promoção da vida humana em condições sadias e com dignidade.

\section{A NATUREZA JURÍdICA DOS ANIMAIS}

Nas últimas décadas surgiu um questionamento crescente a respeito da necessidade de se conferir uma natureza jurídica distinta aos seres não humanos que compõem a fauna (animais), como forma de se concretizar uma proteção mais efetiva desses seres, em respeito às próprias normas ambientais do atual sistema constitucional.

Não há dúvidas de que o que se pretende com o debate acerca da natureza jurídica dos animais é tornar a sua proteção mais eficiente, tornando essa tutela um fim em si mesmo (uma finalidade imediata), e não somente um meio indireto (finalidade mediata) para se proteger o direito dos seres humanos ao meio ambiente ecologicamente equilibrado. O intento subjacente a essa questão, por conseguinte, é a de que, ao se afastar o paradigma antropocêntrico do nosso ordenamento jurídico e da nossa cultura civilizacional, a conservação do meio ambiente e dos seres viventes não humanos venha a se concretizar em patamares mais razoáveis.

O antropocentrismo, nessa ordem de ideias, passa a ser o paradigma cultural e jurídico a ser combatido e superado para que a tutela ambiental prometida nas normas constitucionais e infraconstitucionais se efetive, como se toda a degradação ambiental do atual sistema capitalista de livre mercado, baseado no materialismo e no consumo irrefletido, fosse oriunda dessa cosmovisão de origem aristotélica (FELIPE, 2009) e religiosa (Prevista no primeiro livro da Bíblia dos judeus e dos cristãos, o Gênesis) de que cabe ao homem submeter.

$\mathrm{O}$ art. $225, \S 1^{\circ}$, VII, do texto constitucional de 1988 , parece apoiar esse novo paradigma pois determina a proibição de práticas, cujos únicos destinatários parecem ser os próprios seres que compõem a fauna e a flora, com vistas a se evitar a crueldade e a extinção das espécies. Contudo, nessa defesa a favor da alteração do status jurídico dos animais não se percebe, com o devido respeito, a existência de uma linha teórica e filosófica mais coerente. Há, por exemplo, quem defenda que aos animais deva ser atribuída e reconhecida a personalidade jurídica (como somente há séculos atrás fora conferida aos homens escravos) e há outros que sustentam que devem lhes ser atribuída a possibilidade de serem sujeitos de direitos.

A história não se deixa negar que a personalidade, de fato, é um atributo jurídico mutável, que vai se moldando e transformando de acordo com o curso da história e dos valores vigentes em cada época. A vaca, por exemplo, é considerada um ser sobre-humano de caráter divino em países de determinadas correntes religiosas hinduístas, como a Índia. Naquele país, como é sabido, o animal é colocado em uma posição superior em alguns aspectos a dos próprios seres humanos, que, diga-se de passagem, também possuem a sua capacidade jurídica ampliada ou reduzida a depender, unicamente, da classe social em que nasceram, com base no rígido sistema de castas. 
Dessa forma, insta indagar se a melhor solução seria considerar os animais sujeitos de direitos sem personalidade ou se deveria atribuir-lhes o status de pessoas, conferindo-lhes o atributo da personalidade? $\mathrm{O}$ argumento de que também o ser humano é um animal aqui revela-se convincente. Outro argumento bem persuasivo é o de que os seres humanos escravos já foram considerados bens de propriedade dos homens livres.

Fiuza e Gontijo (2015) afirmam, contudo, que personalidade não se confunde com capacidade de direito ou com o conceito de sujeito de direito. Segundo as lições desses autores, a capacidade traz a medida da personalidade, porquanto uma pessoa pode ser plenamente capaz, relativamente incapaz para a prática de determinados atos ou absolutamente incapaz. Já um nascituro, uma massa falida ou um espólio são sujeitos de direitos, mas que não detêm personalidade, pois não são pessoas físicas ou jurídicas.

Com o devido respeito aos defensores dos direitos dos animais, entende-se acertado o entendimento externado por Fiúza e Gontijo (2015) no sentido de que os animais só podem ser enquadrados como objetos de direito, porquanto se tornaria impossível atribuir personalidade a todos os animais ante a vastíssima diversidade de espécies existentes, que impede de definir quais espécies poderiam ser consideradas pessoas e se a todos seriam garantidos os mesmos direitos.

E, segundo o referido civilista, tampouco seria possível lhes atribuir a sujeição de direitos em face do fato de serem, não raras vezes, objeto de propriedade de outra pessoa, além da impossibilidade clara de se lhes atribuir direitos patrimoniais ou thes imputar qualquer responsabilidade por seus atos.

Não se está aqui a negar a sensibilidade e até mesmo uma certa e limitada consciência (senciência) por parte de algumas espécies animais, mas o fato é que a vida humana prosperou em detrimento de outras espécies extintas (por causas naturais ou por motivos antrópicos) justamente em razão da sua maior racionalidade, consciência e capacidade de se comunicar, que traz para a espécie humana uma possibilidade muito maior de realizações, mas também, de sofrimento.

Não restam dúvidas, portanto, de que, se uma determinada espécie animal (gafanhotos e outras pragas) deve ser exterminada por ter impactado o meio ambiente e gerado um desequilíbrio ambiental, afetando, por conseguinte, as vidas humanas em uma determinada região, não se têm dúvidas de que as vidas humanas devem ser priorizadas. Não há dúvidas, outrossim, de que a vida humana deve ser preservada em uma região afetada pela fome em que o único recurso natural para a sua alimentação sejam algumas espécies animais, mesmo que corram o risco de extinção.

\section{OS LIMITES DOS DIREITOS CULTURAIS E RELIGIOSOS DOS HUMA- NOS EM FACE DOS NÃO HUMANOS}

Esclarecida a impossibilidade de se alterar a natureza jurídica e o reconhecimento da condição (status) de objeto de direito dos animais no atual ordenamento jurídico pátrio, mister que se passe a analisar os limites dos direitos culturais e religiosos do homem ante a preservação dos seres não humanos que compõem a fauna.

A atual CRFB fez a clara opção por seguir a linha antropocêntrica moderada, sobretudo com o advento da Emenda Constitucional n ${ }^{\circ}$ 96, de 2017, que incluiu o parágrafo $7^{\circ}$ do art. 225 para deixar expresso que não são cruéis as práticas desportivas que utilizem animais, desde que sejam manifestações culturais e se assegure o bem-estar dos animais envolvidos. Vê-se aqui claramente a opção que o legislador constituinte fez de permitir que os animais sejam utilizados em manifestações culturais, prestigiando os direitos culturais do homem e o patrimônio cultural brasileiro em detrimento.

Mesmo as normas infraconstitucionais que traçam os limites para se assegurar o bem-estar dos animais e para se evitar os atos gratuitos de crueldade tem como destinatário o próprio homem, pois ao se sujeitar a esse tipo de atividade a pessoa estaria a ferir a própria dignidade humana, que não pode ser alienada ou renunciada, sob pena de violação a um dos fundamentos da República Federativa do Brasil.

Tais posicionamentos não afastam a norma constitucional que veda as práticas que submetam os animais à 
crueldade. Inclusive foi a partir dessa norma que o Supremo Tribunal Federal (STF) considerou inconstitucional a manifestação cultural da Farra do Boi realizada no Estado de Santa Catarina (Recurso Extraordinário $n^{\circ}$ 153.531/1998), em razão das práticas efetivamente adotadas contra os animais, cujo controle estava escapando ao poder de polícia do Estado. Como forma de reconhecer e possibilitar novamente as manifestações culturais envolvendo animais, foi recentemente publicada a Lei $\mathrm{n}^{\circ}$ 13.873, em 17 de setembro de 2019 que alterou os arts. $1^{\circ}, 2^{\circ}$ e $3-B$ da Lei 13.364/2016, preceituando:

Art. $1^{\circ}$ Esta Lei reconhece o rodeio, a vaquejada e o laço, bem como as respectivas expressões artísticas e esportivas, como manifestações culturais nacionais, eleva essas atividades à condição de bens de natureza imaterial integrantes do patrimônio cultural brasileiro e dispõe sobre as modalidades esportivas equestres tradicionais e sobre a proteção ao bem-estar animal. - Redação dada pela Lei no 13.873 , de 2019).

Art. $2^{\circ} \mathrm{O}$ rodeio, a vaquejada e o laço, bem como as respectivas expressões artísticas e esportivas, são reconhecidos como manifestações culturais nacionais e elevados à condição de bens de natureza imaterial integrantes do patrimônio cultural brasileiro, enquanto atividades intrinsecamente ligadas à vida, à identidade, à ação e à memória de grupos formadores da sociedade brasileira - Redação dada pela Lei $n^{\circ}$ 13.873, de 2019 (BRASIL, LEI no 13.354/2016; Arts. $1^{\circ}$ e $2^{\circ}$ ).

Por sua vez, o art. 3-B da Lei 13.364 de 2016, incluído pela Lei no 13.873, de 17 de setembro de 2019, faz um claro esforço para compatibilizar a proteção e o bem-estar dos animais com os direitos culturais dos homens, materializado nas festas de rodeio, na vaquejada e no laço. Vale transcrever na sua totalidade o referido dispositivo:

Art. $3^{\circ}$-B. Serão aprovados regulamentos específicos para o rodeio, a vaquejada, o laço e as modalidades esportivas equestres por suas respectivas associações ou entidades legais reconhecidas pelo Ministério da Agricultura, Pecuária e Abastecimento - Incluído pela Lei no 13.873, de 2019.

$\int 1^{\circ}$ Os regulamentos referidos no caput deste artigo devem estabelecer regras que assegurem a proteção ao bem-estar animal e prever sanções para os casos de descumprimento - Incluído pela Lei $\mathrm{n}^{\circ} 13.873$, de 2019.

\ $2^{\circ}$ Sem prejuízo das demais disposições que garantam o bem-estar animal, deve-se, em relação à vaquejada - Incluído pela Lei no 13.873 , de 2019.

I - assegurar aos animais água, alimentação e local apropriado para descanso - Incluído pela Lei $\mathrm{n}^{\circ} 13.873$, de 2019.

II - prevenir ferimentos e doenças por meio de instalações, ferramentas e utensílios adequados e da prestação de assistência médico-veterinária -- Incluído pela Lei no 13.873, de 2019.

III - utilizar protetor de cauda nos bovinos; (Incluído pela Lei nº 13.873, de 2019)

IV - garantir quantidade suficiente de areia lavada na faixa onde ocorre a pontuação, respeitada a profundidade mínima de $40 \mathrm{~cm}$ (quarenta centímetros) - Incluído pela Lei nº 13.873, de 2019 (BRASIL, LEI $n^{\circ} 13.354 / 2016$; Arts. $3^{\circ}-B$; $\iint 1^{\circ}$ e $2^{\circ}$; Incisos I a IV).

Em que pese o claro esforço da legislação mais recente, é importante se perceber que na ponderação entre os bens jurídicos materializados na proteção dos animais e a promoção dos direitos culturais, o STF, no julgamento da Farra do Boi, havia feito uma clara opção pela proteção dos animais. Verificado o posicionamento da Suprema Corte a favor da proteção dos animais em desfavor dos direitos culturais, importante seja adiante analisado o entendimento adotado por essa mesma Corte em relação à proteção dos animais frente aos direitos religiosos.

No tocante aos limites de proteção dos animais frente aos direitos religiosos, importante registrar que a questão da (in)constitucionalidade dos sacrifícios de animais como prática de culto religioso foi colocada em pauta recentemente para a análise do STF, no julgamento do Recurso Extraordinário $n^{\circ}$ 494.601/2017, em sede do qual se discutia a validade da Lei estadual gaúcha de no 12.131/2004 que afastava a proibição de tratamento cruéis aos animais, previsto de forma expressa no Código Estadual de Proteção 
aos Animais (Lei no 11.941/2003), no caso de sacrifício ritual de animais em cultos e liturgias religiosas de matriz africana.

O julgamento da Corte Suprema foi surpreendemente unânime e a tese extraída desse precedente foi a seguinte: "É constitucional a lei de proteção animal que, a fim de resguardar a liberdade religiosa, permite o sacrifício ritual de animais em cultos de religiões de matriz africana" (Recurso Extraordinário n ${ }^{\circ}$ 494.601/2017). A surpresa em relação à unanimidade do julgamento se deve ao fato de que, como bem pontuado por Leite (2013).

A liberdade religiosa não assegura que uma conduta, apenas porque religiosamente motivada, terá tratamento excepcional em relação às normas estatais com as quais se encontra eventualmente em conflito - o que também não está totalmente excluído, dependendo a solução da controvérsia da análise de outros fatores relevantes ao caso (LEITE, 2013, p. 171).

Apesar da tese consagrada se referir expressamente somente aos cultos de origem africana, talvez em razão de sofrerem claramente um maior preconceito, não se pode esquecer que as religiões judaica, islâmica e hinduísta (JUSBRASIL, 2019), que não possuem origem ou uma preponderante influência do continente africano, também praticam o sacrifício ritual de animais e, por conseguinte, merecem receber o mesmo tratamento jurídico concedido pelo STF aos cultos de matriz africana, em acato ao caráter laico do Estado brasileiro (BRASIL. CRFB, Art. 19, Inciso I), que deriva do princípio jurídico da isonomia na dimensão religiosa.

Frise-se que a liberdade de crença não envolve apenas o direito de ter uma crença, mas de se determinar e cultuar de acordo com ela, como lembrado por Leite (2013), referente ao art. $5^{\circ}$, VI, do texto constitucional, afirmando que é claro ao determinar a inviolabilidade "da liberdade de consciência e de crença, assegurando o livre exercício dos cultos religiosos e garantida, na forma da lei, a proteção aos locais de culto e a suas liturgias" (LEITE, 2013, p. 167).

A proteção ao culto religioso também se encontra claramente consagrada na imunidade religiosa de impostos, prevista no art. 150, VI, "b”, da CRFB/1988, que veda que qualquer ente da federação crie impostos que incidam sobre as atividades das organizações religiosas. Perceba-se que tal garantia fundamental do contribuinte tem como intuito não só manter a equidistância estatal em relação às diversas religiões (como preconiza a laicidade do Estado brasileiro), mas também, manter a salvo dos distúrbios da tributação a livre prática de atividades espirituais inerentes ao culto de caráter religioso.

Também nessa esteira, o Código de Processo Civil, no seu artigo 244, I, veda que se faça a citação, salvo para evitar o perecimento do direito, de quem estiver participando de ato de culto religioso. Tais normas de estatura constitucional e infraconstitucional, respectivamente, deixam claro a intenção do legislador de proteção da liberdade religiosa em todas as suas manifestações e dimensões, sejam intangíveis ou tangíveis.

Veja-se, ante todo o expendido, que o STF possui um posicionamento mais rígido em relação à vedação das práticas cruéis em relação aos animais motivadas por questões culturais do que por questões religiosas. A expressão alegre que dá nome à Farra do Boi contrasta com a expressão Sacrifício de Animais e parece deixar claro que a verdadeira crueldade vem da intenção de se obter um divertimento por meio de uma prática que causa um mal ao animal; não sendo cruel a atividade quando se acredita que a morte e a dor do animal são necessárias para se agradar a uma esfera transcendental-espiritual.

Verificados os limites da proteção aos seres não humanos ante as esferas de direitos e garantias religiosas e culturais, importante se passe a analisar se o direito ao desenvolvimento econômico de fato representa necessariamente uma força antagônica à concretização dos direitos dos animais.

\section{OS LIMITES IMPOSTOS PELOS DIREITOS ECONÔMICOS DOS HUMA- NOS EM FACE DOS NÃO HUMANOS}


Há, de fato, uma massificada e até certo ponto justificada percepção de que a economia é o grande inimigo e desafio na busca do equilíbrio ecológico e da utilização racional dos recursos naturais. Igualmente se revela incontestável o fato de o homem ser o maior responsável pela extinção das outras espécies de animais e, portanto, o seu maior algoz. Não se nega, por conseguinte, o que Vaz (1992, p. 646) já vaticinava no ano de 1992, no sentido de que os "textos destinados à proteção dos recursos naturais, da fauna, da flora e à vedação de atividades poluentes revelaram toda a sua fragilidade diante dos interesses econômicos maiores."

Contudo, para se afastar percepções equivocadas e mal concebidas, não se pode perder de vista que o desenvolvimento da economia depende da ecologia. Ou seja, há um limite para a degradação ambiental que, se ultrapassado, afeta diretamente o próprio crescimento econômico e põe em risco a saúde e até mesmo a própria existência da vida humana.

Um exemplo claro disso são os recentes desastres ambientais em razão das alterações climáticas que geram prejuízos econômicos bilionários (GLOBO, 2019), além de causar de forma trágica a morte de milhões de pessoas (NACOESUNIDAS, 2019) e o êxodo de milhões de refugiados ambientais, colocando em cheque o atual modelo econômico que, ao que tudo indica, se não for alterado, contém em si o germe da sua própria destruição. Nesse sentido, Oliveira da Silva afirma que

[...] uma das provas da atual crise do capitalismo ser estrutural é o fato de ela atuar sobre o esgotamento do modelo de produção e consumo, que é altamente degradante do meio ambiente.

Portando, na origem da crise ecológica está o modo de desenvolvimento conduzido sem outro critério que não seja o da rentabilidade máxima do capital. Destarte, a tendência ilimitada à produção não é uma consequência natural da espécie humana, mas particular da produção capitalista, visto que é o resultado direto e necessário de uma organização econômica que gira em torno da produção de lucro e não da satisfação das necessidades dos seres humanos. Por essa razão, é impossível entender a crise ambiental sem partir da compreensão da dinâmica econômica da sociedade capitalista (OLIVEIRA DA SILVA, 2013, p. 127).

Por isso, a natureza não pode mais ser encarada como simples instrumento ou utilidade; antes deve ser compreendida economicamente, com a mesma urgência que a economia deve ser compreendida ecologicamente, sob pena de não se alcançar uma política econômica e tampouco uma política ambiental eficiente.

Nesse sentido, há somente uma aparente relação dicotômica entre economia e ecologia e um falso antagonismo entre o homem e a natureza. Não se pode olvidar que os recursos naturais e os seres não humanos são a matéria prima da atividade econômica. Disso se pode inferir que essa crise ambiental atualmente posta é de natureza eminentemente econômica. Não é outro o entendimento de Antunes, quando salienta a existência de uma irreal dicotomia, afirmando que

Economia e ecologia têm muita coisa em comum, pois têm origem na palavra oikos, casa. No entanto, tal relação óbvia não tem tido aceitação entre as partes envolvidas, existindo sempre a irreal dicotomia entre "desenvolvimento e meio ambiente". Fato é que as relações entre economia e ecologia têm sido muito tensas e, especialmente, no Direito Ambiental, elas não têm tido a atenção que merecem (ANTUNES, 2010, p 170).

O meio ambiente, portanto, além de ser a fonte de todos os seres vivos e os recursos naturais que servem para a produção de bens e serviços, provê ainda as condições necessárias para a manutenção da vida, bem como, absorve todos os resíduos provenientes da produção e do consumo. A proteção ambiental é, dessa forma, um verdadeiro pressuposto para o alcance de todos os outros objetivos constitucionais, inclusive os objetivos de concretização dos direitos socioeconômicos, como o desenvolvimento nacional e a redução das desigualdades regionais.

A ordem econômica, nesse contexto de ideias, deve se fundar na valorização do trabalho humano, na livre iniciativa e na justiça social, além de observar, entre outros princípios, o da defesa do meio ambiente, 
com base no art. 170, VI, da CRFB.

Art. 170. A ordem econômica, fundada na valorização do trabalho humano e na livre iniciativa, tem por fim assegurar a todos existência digna, conforme os ditames da justiça social, observados os seguintes princípios:

$[\ldots]$

VI - defesa do meio ambiente, inclusive mediante tratamento diferenciado conforme o impacto ambiental dos produtos e serviços e de seus processos de elaboração e prestação - Redação dada pela Emenda Constitucional no 42, de 19.12.2003 (BRASIL, CRFB/1988, Art. 170, Inciso VI) (grifo nosso).

Assim, não é difícil perceber que o princípio preservacionista contido no art. 170, VI da CRFB e o direito fundamental contido no caput do art. 225 devem ser aplicados conjuntamente; nunca de forma setorizada. Passou a ser imprescindível a implementação de uma coordenação sistemática entre as políticas econômicas e as ambientais. Nesse sentido, pontua Derani, afirmando que

Esta visão setorizada não deve prosperar, se se quer tornar efetivos os princípios da Constituição Federal, prescritos, sobretudo, nos seus arts. 170 e 225. Tanto a Constituição não pode ser interpretada aos pedaços como políticas econômicas e ambientais não são livros diferentes de uma biblioteca, manuseados, cada um a sua vez, segundo o interesse e a conveniência de algum leitor (DERANI, 2008, p. 69).

A própria gravidade do atual estágio de degradação dos bens ambientais também deveria romper as concepções mais maniqueístas, que tradicionalmente opõem economistas e ecologistas. A classe social que mais deveria estar interessada na eficiência da gestão ambiental são os próprios empreendedores e estudiosos das ciências econômicas, com vistas a assegurar o equilíbrio ambiental que possibilita o acesso sustentável aos bens ambientais que são a fonte de matéria prima dos seus produtos, além de manter em resguardo uma boa imagem da sua empresa. Pode-se citar, ainda, outros motivos econômicos benéficos para a implantação de práticas sustentáveis, tais como:

i) financiamentos bancários e processos licitatórios; ii) melhoria da imagem da empresa; iii) maior satisfação dos clientes, investidores e consumidores; iv) redução dos riscos de danos ambientais e de passivo ambiental; v) melhoria de desempenho e permanência do produto no mercado; e vi) novos mercados pela reciclagem dos resíduos (D’ISEP, 2009, 178-179).

Como bem realçado por Oliveira (2007, p. 234), "trata-se, pois, de reconhecer que o Meio Ambiente é bem econômico e tem preço, e que não há desenvolvimento que não seja sustentável”. Nessa ordem de ideias, importante não se esquecer da chamada Revolução Verde, ocorrida nos idos de 1960, que, por meio da criação de inovações tecnológicas como defensivos, fertilizantes e técnicas mais eficientes de plantio e criação de animais, conseguiu evitar a tenebrosa previsão malthusiana de uma fome planetária, que estava fundamentada no crescimento populacional vertiginoso pós-Revolução Industrial.

Se por um lado foi superada a previsão malthusiana de uma fome generalizada, por outro lado não se pode admitir o prosseguimento do atual modelo econômico que tem gerado a extinção de tantas espécies de animais e o uso irracional de recursos naturais. Dessa forma, necessário, seja também, rompida qualquer visão dicotômica na relação entre seres humanos e não humanos, haja vista que a extinção das outras espécies de animais pode ocasionar a extinção da própria existência do bomo sapiens, ou seja, na expressão utilizada pela National Geographic: "dessa vez, os asteroides somos nós” (NATIONALGEOGRAPHICBRASIL, 2019, p. 10)

Contudo, mesmo que houvesse uma proposta de emenda à constituição para se retirar a centralidade do homem e do princípio da dignidade da pessoa humana do sistema jurídico nacional, não se tem dúvidas de que essa alteração seria claramente inconstitucional por colocar em risco os direitos fundamentais do 
homem elencados no art. $5^{\circ}$ e em outros dispositivos do texto constitucional, ferindo, por conseguinte, interesses protegidos por cláusula pétrea.

\section{CONSIDERAÇÕES FINAIS}

De tudo o que foi exposto, foi verificado que o atual ordenamento jurídico nacional impõe claros limites à proteção dos animais e à proposta de alteração da condição jurídica desses seres não humanos. $\mathrm{O}$ caráter antropocêntrico moderado do sistema constitucional brasileiro, as dificuldades da corrente teórica defensora dos direitos dos animais em alinhar uma tese jurídica mais coerente, bem como, a complexidade da tarefa para se definir quais seres não humanos seriam incluídos nesse novo status jurídico revelam-se verdadeiras barreiras que estão a dificultar sobremaneira o avanço dessa discussão.

Verificou-se que o STF possui um posicionamento mais favorável à proteção do bem-estar e da vida dos animais quando em confronto com os direitos culturais, como externado no caso envolvendo os maustratos na Farra do Boi. Já em relação aos direitos religiosos, aquela mesma Suprema Corte se colocou de forma mais desfavorável à proteção dos animais, considerando constitucional a prática religiosa dos cultos africanos de realizar o sacrifício de animais, considerando inexistir crueldade nesse caso ante o respeito à liberdade de crença e de manifestação religiosa dos praticantes desse ritual.

No tocante aos direitos econômicos, incluído o direito ao desenvolvimento, ficou registrada a importância de não mais se enxergar a relação entre economia e ecologia de forma dicotômica, já que a natureza é a fonte de todos os recursos utilizados para a produção econômica e a fonte da própria subsistência do homem.

Não se está com isso negando que o atual modelo econômico baseado na degradação ambiental e no consumo desenfreado deva ser substituído por um modelo mais sustentável, como ordena a própria CRFB. Muito pelo contrário, está se buscando justamente reforçar que o atual modelo põe em risco a dignidade, a saúde e a vida do próprio homem.

O que não se pode aceitar juridicamente, ante o caráter antropocêntrico do sistema jurídico nacional, é que a subsistência, a saúde e a dignidade de toda uma comunidade humana não sejam preservadas e promovidas quando em confronto à vida e o bem-estar de outras espécies animais. Por isso, entende-se inconstitucional qualquer proposta de emenda à constituição ou mesmo lei infraconstitucional que retire a centralidade do homem e dos seus direitos e garantias do sistema jurídico pátrio, por se tratar de interesses e bens protegidos por cláusula pétrea.

\section{REFERÊNCIAS}

ANTUNES, Paulo de Bessa. Direto Ambiental: aspectos fundamentais. In: FARIAS, Talden; COUTINHO, Francisco Seráphico da Nóbrega (coords.). Direito Ambiental: o meio ambiente e os desafios da contemporaneidade. Ed. Fórum: Belo Horizonte, 2010.

BRASIL. Constituição da República Federativa do Brasil. Brasília: Senado Federal, 1988. Disponível em: <http://www.planalto.gov.br/ccivil_03/constituicao/_ConstituiçaoCompilado.htm>. Acesso em: 21 nov. 2019.

. STF - RE no 153.531, Relator(a): Min. MARCO AURÉLIO, julgado em 03/06/1997, publicado em DJ 13/03/998 PP-388. Disponível em: http://redir.stf.jus.br/paginadorpub/paginador.jsp?docTP=AC\&do$\mathrm{cID}=211500$.

. STF - RE no 494.601, Relator(a): Min. MARCO AURÉLIO, julgado em 24/08/2017, publicado em DJ 13/03/998 PP-388. Disponível em: https://www.jusbrasil.com.br/processos/132684842/processo-n-494 601-do-stf.

. Lei $\mathrm{n}^{\mathrm{0}} \mathbf{1 3 . 3 6 4}$, de 29 de novembro de 2016. Reconhece o rodeio, a vaquejada e o laço, bem como as respectivas expressões artísticas e esportivas, como manifestações culturais nacionais; eleva essas 
atividades à condição de bens de natureza imaterial integrantes do patrimônio cultural brasileiro; e dispõe sobre as modalidades esportivas equestres tradicionais e sobre a proteção ao bem-estar animal. (Redação dada pela Lei no 13.873, de 2019). Disponível em: http://www.planalto.gov.br/ccivil_03/_ato20152018/2016/lei/ L13364.htm.

Lei $\mathbf{n}^{\mathbf{0}}$ 13.873, de 17 de setembro de 2019. Altera a Lei $\mathrm{n}^{\circ}$ 13.364, de 29 de novembro de 2016, para incluir o laço, bem como as respectivas expressões artísticas e esportivas, como manifestação cultural nacional, elevar essas atividades à condição de bem de natureza imaterial integrante do patrimônio cultural brasileiro e dispor sobre as modalidades esportivas equestres tradicionais e sobre a proteção ao bem-estar animal. Disponível em: http://www.planalto.gov.br/ccivil_03/_Ato2019-2022/2019/Lei/L13873.htm

Lei n $\mathbf{n}^{\mathbf{1 3}}$ 13.105, de 16 de março de 2015. Código de Processo Civil. Disponível em: http:/ /www.planalto.gov.br/ccivil_03/_ato2015-2018/2015/lei/113105.htm.

DERANI, Cristiane. Direito Ambiental Econômico. $3^{a}$ ed. São Paulo: Saraiva, 2008.

D’ISEP, Clarissa Ferreira Macedo. Direito Ambiental Econômico e a ISO 14000. 2. ed. São Paulo: Revista dos Tribunais, 2009.

FELIPE, Sônia T. Antropocentrismo, sencientismo e biocentrismo: perspectivas éticas abolicionistas, bemestaristas e conservadoras e o estatuto de animais não-humanos. São Paulo. Revista Páginas de Filosofia, v. 1, n. 1, jan-jul/ 2009.

FIUZA, César Augusto de Castro e GONTIJO, Bruno Rezende Azevedo. Proteção Ambiental e Personificação dos Animais. Veredas do Direito: Direito Ambiental e Desenvolvimento Sustentável, Belo Horizonte, v. 11, n. 22, p. 71, ago. 2015.

GLOBO.COM. Mudanças climáticas causaram prejuízo de 85 bilhões no mundo em 2018. Disponível em: <https://oglobo.globo.com/sociedade/mudancas-climaticas-causaram-prejuizo-de-us-85-bilhoesno-mundo-em-2018-23330714> Acesso em: 21 de nov. de 2019.

HABERMAS, Jurgen. Direito e Democracia: entre facticidade e validade. V.2. Trad. Flávio Beno Siebeneichler. Rio de Janeiro: Tempo Brasileiro, 1997, passim.

JUSBRASIL.COM.BR. O sacrifício religioso de animais. Disponível em: https://pedrosampaio85.jusbrasil.com.br/artigos/491175718/o-sacrificio-religioso-de-animais Acesso em: 19 de nov. de 2019.

LEITE, Fábio Carvalho. A liberdade de crença e o sacrifício de animais em cultos religiosos. Veredas do Direito: Direito Ambiental e Desenvolvimento Sustentável, Belo Horizonte, v. 10, n. 20, Dez. 2013. NACOESUNIDAS.ORG. Poluição causa 126 milhões de mortes por ano alerta agência ambiental da ONU. Disponível em: <https://nacoesunidas.org/poluicao-causa-126-milhoes-de-mortes-por-anoalerta-agencia-ambiental-da-onu/> Acesso em: 21 de nov. de 2019.

NATIONALGEOGRAPHICBRASIL.COM. O que perdemos com a extinção dosa animais. Disponível em: <https://www.nationalgeographicbrasil.com/animais/2019/10/o-que-perdemos-com-extincaodos-animais> Acesso em: 11 de dez. de 2019.

OLIVEIRA, José Marcos Domingos de. Direito Tributário e Meio Ambiente. $3^{\text {a }}$ ed. Rio de Janeiro: Forense, 2007.

OLIVEIRA DA SILVA, Maria Beatriz. Crise Ecológica e Crise(s) do Capitalismo: o Suporte da Teoria Marxista para a Explicação da Crise Ambiental. Veredas do Direito: Direito Ambiental e Desenvolvimento Sustentável, Belo Horizonte, v. 10, n. 19, p. 115, set. 2013.

RIO GRANDE DO SUL. Lei $\mathbf{n}^{\circ}$ 12.131, de 22 de julho de 2004. acrescenta Parágrafo Único ao Artigo $2^{\circ}$ da Lei no 11.915, de 21 de maio de 2003, que institui o Código Estadual de Proteção aos animais, no âmbito do estado do Rio Grande do Sul. Disponível em: https://leisestaduais.com.br/rs/lei-ordinaria-n-121312004-rio-grande-do-sul.

Lei n ${ }^{\circ}$ 11.941, de 10 de julho de 2003. Acrescenta o $\int 4^{\circ}$ ao Art. 22 da Lei Estadual no 11.424, de 06 de janeiro de 2000. Disponível em: https://leisestaduais.com.br/rs/lei-ordinaria-n-11941-2003-riogrande-do-sul-acrescenta-4-ao-art-22-da-lei-estadual-n-11424-de-6-de-janeiro-de-2000.

VAZ, Isabel. Direito Econômico das Propriedades. 1. ed. Rio de Janeiro: Forense, 1992. 